\title{
The Importance Of Scientific Research: The Case Of Insurance For Climate Change
}

\author{
Donatella Porrini
}

Associate Professor of Economic Policy - Department of Economic Science- Università del Salento

Abstract: Climate change is likely to cause extreme weather events in the world with the consequence of an increased number of natural catastrophes. The expected damages pose serious challenges to governments in terms of policy choice and a crucial point is to define the role can be played by insurance sector, particularly as a tool to reduce potential damage, as well as to stimulate mitigation. Scientific research and good knowledge of risk are necessary in guiding policy decisions to manage the risks deriving from climate change. In this direction, the author analyses the fact that risks connected with climate change and the potential contribution of the insurance sector need to be analysed by scientific research in order to plan the correct risk management strategies in the future.

Keywords: climate change;insurance;risk management;natural catastrophes

\section{Introduction}

The Intergovernmental Panel on Climate Change (IPCC) provides that climate change is likely to cause natural catastrophes in the world. Particularly, global warming will increase the frequency of heavy precipitations, the incidence of extremely high sea level, the intensity of tropical cyclone activity as well as flooding and landslides (IPCC, $\left.2014^{[1]}\right)$. Therefore, given to climate change and the consequent increase in number of disasters over the years, we expect a rise in life losses and damage to properties with long-lasting financial and non-financial impact.

Several studies have examined the role that can be played by the insurance sector, particularly within the policy choice issue to tackle climate change consequences (Kunreuther, $1996^{[2]}$ ).

Climate change policies, which usually focus on large-scale engineering infrastructure, in recent years, have increasingly moved to a more integrated approach that aims at both disasters mitigation, through disaster risk management plans, and adaptation actions to reduce the impacts. Because the focus is more on the management of risk, a growing interest is for the insurance products and their contribution to compensate damage, and generally for risk transfer instruments for their financial support to existing protection measures

On one hand, it has been demonstrated that insurance plays a key role in promoting private investments so as to contribute mitigation measures addressed to significantly reduce damage through the incentive to risk reduction (Mills, $2009^{[3]}$ ). But, on the other hand, practical experience suggests that people who live in risk-prone areas do not always insure voluntarily, even in the case of high vulnerability to disasters

Copyright (C) 2017 Donatella Porrini

doi: $10.18686 /$ fm.v2i2.970

This is an open-access article distributed under the terms of the Creative Commons Attribution Unported License

(http://creativecommons.org/licenses/by-nc/4.0/), which permits unrestricted use, distribution, and reproduction in any medium, provided the original work is properly cited. 
The fact that the penetration of insurance products is still at a low level is explained in different ways such as the inadequate risk awareness, the perception of natural hazards as events characterised by low frequency, the state relief and compensation considered as granted, the too high level of insurance premiums, the lack of provision for a mandatory insurance, the reduced effort by private insurance companies to promote financial products covering unexpected catastrophic losses, and so on (Kunreuther \& Pauly, 2004 ${ }^{[4]}$ ).

For all these reasons, in many countries insurance systems are not sufficiently developed and, relatively to the risks deriving from climate change, the insurance sector faces difficulties in defining the legitimacy of this role.

To manage the future risks connected with climate change, it is relevant the scientific knowledge to define a proper role for the insurance sector, making clear to external stakeholders, and especially political decision makers, the legitimacy of its role, and highlighting the need of developing and marketing of products and services to manage the risks effectively (Geneva Association, 2009 ${ }^{[5]}$ ).

To address this topic, we define in the next paragraph the role that can be played by the insurance sector in relation with climate change; then the third paragraph investigates the issue of risk knowledge; we conclude with considerations about the future of scientific research.

\section{Insurance and climate change}

The effects of natural disasters in terms of economic losses could be significant for private and public properties and insurance appears as one option to cover, at least partially, the monetary impacts of the disasters. In practise, the uncertainty of a loss is transferred to the insurance companies, that in return receive payment in form of premiums from the policyholders.

"Insurance systems with comprehensive coverage and uptake offer some advantages as compared to alternative damage compensation instruments: i) insurance is not restricted by a liability framework; ii) insurance removes uncertainty compensation and eligibility requirements (v. contingency funds); and iii) insurance is (at least partially) funded by policyholders, thus relieving pressure on the public budget (v. conventional public contingency funds/state aid). Furthermore, insurance mechanisms based on risk-based pricing introduce incentives for risk-mitigating behaviour (Surminski et al., 2015 ${ }^{[6]}$ )" (Carraro, 2016, p. $1^{[7]}$ ).

If and how insurance is used to cover natural disasters economic consequences in a country depends on different factors, such as national traditions, cultural attitudes, past incidence of disasters, the availability of scientific data, as well as the involvement of public and private sector.

In each country, the natural disasters insurance system presents different features in terms of the relationship between public and private actors: there can be a public and private partnership; the state can provide only subsidises; the principle of solidarity can be central or risk-based market mechanisms can be applied (Porrini and Schwartze, 2014 ${ }^{[8]}$ ).

Taking as an example the situation in Europe, some countries, such as in the Netherlands, provide only for a public compensation schemes, where the public compensating system for natural disasters offer a partial compensation for damage to property-owners and businesses under certain conditions. Other countries, such as France, are characterized by a public insurance system, funded by a mandatory fee included in the private property and casualty insurance; the private insurers are responsible for compensating the natural hazard risks, but public actors provide for the reinsurance and for a system of natural disaster prevention and mitigation. In other countries, such as in Germany, the main role is played by private actors, with the state playing a regulatory role, but not facing any financial risks. In the United Kingdom, there is a form of public-private partnership, where private insurance companies provide damage coverage in exchange for public investment in risk prevention.

Furthermore, insurance is also play a role in a risk management system addressed to implement the identification and 
the assessment of risks in order to define a set of actions with the aim to minimising the economic damages caused by catastrophic events implementing strategies and actions to control and reduce risk.

Over the last decades, risk management of natural hazards has rapidly spread and developed. The focus has changed from ex-ante prevention strategies and ex-post compensation strategies, to a recently emerging, more holistic vision related to the concept of resilience (Ghesquiere et al., 2006 ${ }^{[9]}$ ).

In this sense we can say that insurance sector is in charge to contribute to a system of prevention and risk transfer to support economically individuals and businesses to face major risks, where possible avoiding those that are too large, mitigate the consequences and locate the resources in advance to cover the damages from the natural disasters. This is the aim of a risk management system for coping with climate change risks.

Particularly for the link between insurance and disaster risk management, this topic is also gaining attention on the scientific research ground, where the focus is on the role of insurance to support mitigation and climate resilience.

\section{The issue of the risk knowledge through scientific research}

Speaking about the climate change issue, we live with natural processes that are periodically hazardous, we face consequences that are uncertain and we may result better or worse off: that is what we call "risk". "Risk" arises not just from how some future can be described, but from the uncertainty that characterised that description.

In fact, the concept of "risk" is central in the climate change policy debate.

On a scientific point of view, we can define "risk" merely in terms of the kind of events or activities we would commonly call risky, but we can also define "risk" in terms of processes. The process that is very commonly discussed in the scientific literature on climate change insurance is "risk perception" (Bubeck et al. 2012[10]) that implies a definition of something to be perceived. But, for what concerns the risk management of climate change consequences, the process to be addressed is the one of "risk knowledge", that refers, more neutrally, to how scientific research anticipate the outcomes of different events.

We can say that knowledge of risk is a special case of the interpretation of uncertain information, and "risk-taking", "preparing" and "avoidance" are special kinds of actions chosen under conditions of uncertainty (Eiser et al. 2012 ${ }^{[11]}$ ). Such information is analysed and actions are chosen depending considerably on the scientific research that is conducted on the topics related with the definition of the risk.

Another important distinction within the concept of "risk", particularly connect with catastrophic events, is between epistemic risk and aleatory risk. "Epistemic risk (from the Greek word 'episteme' meaning knowledge) arises from our lack of knowledge about the appropriate model or theory that might be valid or relevant for a particular phenomena, and aleatory risk (from the Latin root 'aleator' for dice player) arises from randomness inherent in a phenomena (though this randomness itself may be defined or qualified by the underlying epistemic assumptions made)" (Kleindorfer, 2010 ${ }^{[12]}$ ).

Dealing with insurance for climate change, we can address by scientific research the epistemic risk trying to have more knowledge that could help the building of risk management strategies, but for what concerns the aleatory risk this gives rise to an uncertainty that will remain "unmanaged".

For example, in predicting the real effects of heavy precipitations, recurrence rates for flood activity, for the rise of the water level and for geological conditions, and the contents and fragility of buildings all represent epistemic assumptions that insurance models need to derive from scientific research and analysis. But, in addition to these sources of epistemic uncertainty, there is a natural randomness associated with the effects of every natural disaster and such randomness would remain unknown even if one knows when and where floods would occur, the complete geology of a particular region and all relevant features of affected buildings. 
There is a grey area in the definition of epistemic and aleatory risk, but the main difference is that epistemic risk can be limited through scientific research and the consequent knowledge, using better theory and better data, whereas aleatory risk remains unknown and scientific activities do not help to discover it. This is a fundamental difference that has given rise to a certain kind of approaches to decision making under uncertainty that are based on the value of information and model-based estimation issues.

Balancing and integrating the best available scientific judgements and evidence on the one hand with aspects of "financialization" of natural hazard costs on the other hand, is perhaps one of the most difficult questions to be faced by governments and their regulators today.

"Historically, of course, this balance has often been struck more by default than by conscious deliberation, through the many and varied political processes operating within different societies. Today, however, a more explicit if no less difficult challenge faces the policy maker, as social science research points to some of the characteristics of hazards, and aspects of risk-managing institutions, which might drive public concerns" (Pidgeon, 1998 ${ }^{[13]}$ ).

More researches are needed in the future for their relevant implications for the way risk judgements are designed in our contemporary societies and the research challenge is the finding of appropriate methodologies and data that result in open and accountable processes for characterising and deciding about the management of climate change risks through the insurance sector.

\section{Conclusive remarks on future trend}

This paper addresses the question of whether the findings from scientific research on insurance and natural hazards are connected with the building of a risk management system to face climate change consequences.

Given that good science and careful assessments of risk are necessary conditions for guiding policy decisions, investigations of what is to be regarded as a "risk", and hence how we are to manage risks, are a matter of scientific research.

Certainly the general issue of catastrophe insurance covering the damages from climate change risks, be they from flood, storm, tornado, hurricane, cyclone, avalanche, typhoon, landslide, is now well understood. Indeed, we now need a more complex risk managing system for generally weather-related risks as the ones deriving from climate change, as a common approach to address catastrophe risks based on the character of the underlying hazard, and correlations across insured losses affected by different hazards.

Nonetheless, there is a real urgency, in the current growing awareness of the risks from climate change, to address weather-related catastrophe risks also by providing scientific research contributions that increase our knowledge in the field.

\section{References}

1. IPCC (2014), Climate Change 2014 - Synthesis Report Summary for Policymakers.

2. Kunreuther H. (1996), Mitigating disaster losses through insurance, Journal of Risk and Uncertainty, 12, pp. $171-187$.

3. Mills, E. (2009). From risk to opportunity: Insurers responses to climate change, CERES Report, April.

4. Kunreuther H., Pauly, M. (2004), Neglecting Disaster: Why Don't People Insure Against Large Losses?, Journal of Risk and Uncertainty 28(1), pp. 5-21. http://doi:10.1023/B:RISK.0000009433.25126.87

5. Geneva Association (2009), The Insurance Industry and Climate Change, Geneva, The Geneva Reports - Risk and Insurance Research, n. 2, July.

6. Surminski S., Aerts J.C.J.H., Botzen W.J.W., Hudson P., Mysiak J., Pérez-Blanco C.D. (2015), Reflections on the current debate on how to link flood insurance and disaster risk reduction in the European Union. Nat. Hazards 79, pp. 1451-1479. doi:10.1007/s11069-015-1832-5

7. Carraro C. (2016), Climate change and agricultural losses: what role for insurance?, http://www.carlocarraro.org/en/ 
topics/finance/climate-change-and-agricultural-losses-what-role-for-insurance/

8. Porrini D., Schwartze R. (2014), Insurance models and European climate change policies: an assessment, European Journal of Law and Economics, 38, n. 1, pp. 7-28.

9. Ghesquiere F., Mahul, O. (2007), Sovereign Natural Disaster Insurance for Developing Countries: a Paradigm Shift in Catastrophe Risk Financing Policy, Research Working Paper 4345, World Bank, Washington D.C.

10. Bubeck P., W. J. W. Botzen, J. C. J. H. Aerts (2012), A Review of Risk Perceptions and Other Factors that Influence Flood Mitigation Behavior, Risk Analysis, Vol. 32, No. 9, 2012 DOI: 10.1111/j.1539-6924.2011.01783.x, pp. 1481-1495.

11. Eiser J. R., Bostrom A., Burton I., Johnston D. M., McClure J., Paton D., Van der Pligt J., White M. P. (2012), Risk interpretation and action: A conceptual framework for responses to natural hazards, International Journal of Disaster Risk Reduction, pp. 5-16.

12. Kleindorfer P. (2010), Interdependency of Science and Risk Finance in Catastrophe Insurance and Climate Change, INSEAD Working Papers, 02/2010.

13. Pidgeon N.F. (1998), Risk assessment, risk values and the social science programme: why we do need risk perception research, Reliability Engineering and System Safety, 59, pp. 5-15. 